\title{
Cardiac arrest due to a fatal dose of propranolol successfully treated with intravenous lipid infusion
}

\author{
Edin Botan ${ }^{1 \oplus}$, Tanıl Kendirlii ${ }^{1 \oplus}$, Emrah Gün ${ }^{1 \oplus}$, Serdar Balsak ${ }^{1 \oplus}$, Mehmet Ramoğlu² ${ }^{2 \oplus}$ \\ Ercan Tutar ${ }^{2}$ \\ Divsions of ${ }^{1}$ Pediatric Critical Care Unit and ${ }^{2}$ Pediatric Cardiology, Department of Pediatrics, Ankara University Faculty of Medicine \\ Ankara, Turkey.
}

\begin{abstract}
Background. Beta blockers (BB) are used for very different indications in both adults and children. There can be mild adverse effects with normal doses. When taken in toxic doses, this can have fatal results in children. There are some standard therapies during BB poisoning such as insulin and glucagon but there is not enough knowledge concerning intravenous lipid infusion therapy (ILI).

Case. Herein we present a case of propranolol poisoning in a previously healthy 2-year-old girl. In this patient, cardiac arrest developed twice, and cardiopulmonary resuscitation was performed for 5 and 20 minutes, respectively. We initiated inotropes, insulin, calcium and glucagon with a lack of response to all medical treatment. We used ILI and the patient improved after this treatment. She recovered without any disability.
\end{abstract}

Conclusions. ILI treatment should be considered with life-threatening BB poisoning which is unresponsive to standard therapies.

Key words: beta blockers, poisoning, propranolol, children, intravenous lipid infusion therapy.

Beta blockers (BB) are commonly used drugs in adults but their use in children is rare. ${ }^{1}$ They are frequently used for the treatment of hypertension, ischemic heart disease and arrhythmia in adults. ${ }^{1}$ The indications of BB usage in children include supraventricular tachycardia, atrial fibrillation/flutter, prevention of cyanotic spells in tetralogy of Fallot, thyrotoxicosis, migraine headache prophylaxis and hypertension. ${ }^{1}$ Propranolol, metoprolol, esmolol and carvedilol are the most frequently used BB in children. Propranolol is a non-cardioselective $\mathrm{BB}$ with membrane stabilizing activity. ${ }^{2}$

$凶 \quad$ Edin Botan

edinbotan@hotmail.com

Received 29th May 2020, 2nd September 2020, accepted 3rd December 2020.

This study was presented at the 16th National Pediatric Emergency Medicine and Intensive Care Congress, 2-5 October 2019, Antalya, Turkey.
Intravenous lipid infusion (ILI) treatment is primarily used in poisoning with lipophilic local anesthetic and chemical agents, but there are few reports of its usage in calcium channel blocker (CCB) and BB poisoning. ${ }^{3}$ The use of ILI in propranolol poisoning has rarely been reported in adults and scarcely in children. ${ }^{4}$ Herein we present an infant who was successfully treated by ILI who developed severe cardiac arrest (CA) due to a fatal dose of propranolol ingestion.

\section{Case Report}

A previously healthy 2-year-old girl was brought to our Pediatric Emergency Care Service due to vomiting and drowsiness that had started 6 hours ago. On admission, her Glasgow Coma Scale (GCS) was 6, cardiac arrest developed and we started cardiopulmonary resuscitation (CPR), na intraosseous line was established and one dose of epinephrine was given after endotracheal intubation. Return of spontaneous 
circulation (ROSC) was achieved in 5 minutes. After ROSC the Patient's cebtral pulses were weak and peripheral pulses were absent. The patient was given a high-speed infusion of $0.9 \%$ saline. Blood glucose level was $96 \mathrm{mg} / \mathrm{dL}$. She was transferred to the pediatric intensive care unit (PICU). The patient was monitored, connected to a mechanical ventilator and a central venous catheter was inserted. \% 0.9 Serum Intravenous fluid rescue therapy was given twice at $20 \mathrm{~mL} /$ $\mathrm{kg}$ with rapid saline infusion, epinephrine infusion was started at a dose of $0,1 \mathrm{mcg} / \mathrm{kg} /$ $\mathrm{min}$. The patient's venous blood gases revealed a pH: 7.10, pCO2: 45, pO2: 20.9 HCO3: 13.5, lactate: $5.2 \mathrm{mmol} / \mathrm{L}$, during PICU admission. Biochemical parameters and other blood values were found within normal ranges. Cardiac arrest developed again after 15 minutes of PICU admission. We started CPR again and the patient received adrenaline 7 times and one dose of bicarbonate. The bradycardia continued and 1 $\mathrm{mg}$ of atropine was administered intravenously three times. We prepared for extracorporeal cardiopulmonary resuscitation (ECPR) if spontaneous circulation was not restored. ROSC occurred in 20 minutes and her rhythm was pulsed ventricular tachycardia, therefore we performed electrical cardioversion 3 times as 1-2-2 joule/kg respectively, and amiodarone infusion was started. As the patient's QTc> $0.55 \mathrm{~s}$ on electrocardiography, amiodarone was discontinued. At that time, she required a high dose of inotropic support $(0.3 \mathrm{mcg} / \mathrm{kg} / \mathrm{min}$ of epinephrine, $0.1 \mathrm{mcg} / \mathrm{kg} / \mathrm{min}$ of norepinephrine, $10 \mathrm{mcg} / \mathrm{kg} / \mathrm{min}$ of dopamine).

When the patient's history was deepened, we learned that 5 tablets of her grandmother's drug $\left(40 \mathrm{mg}\right.$, Dideral ${ }^{\circledR}$, propranolol), which is equivalent to $17 / \mathrm{mg} / \mathrm{kg}$ dose, was not in its drug box and we strongly suspected that patient had propranolol poisoning. She received activated charcoal at $1 \mathrm{gr} / \mathrm{kg}$, meanwhile, the patient was hypotensive $(53 / 35 \mathrm{mmHg})$ in spite of the high dose of inotropes and vasopressors, we initiated insulin 1U/kg intravenous bolus and switched to $0.5 \mathrm{U} / \mathrm{kg} / \mathrm{hr}$ infusion. $10 \%$ calcium gluconate infusion at a dose of $1 \mathrm{~mL} / \mathrm{kg}$, and subcutaneous glucagon at a dose of $0.5 \mathrm{mg}$ (because there is no intravenous form) were administered. Despite all attempts findings of decompensated shock continued and we decided to start ILI at the $60^{\text {th }}$ minute of PICU admission. ILI was given at a dose of $1.5 \mathrm{~mL} / \mathrm{kg}$ IV bolus (for 3 minutes) and $0.25 \mathrm{~mL} / \mathrm{kg} /$ hour infusion was started for 30 minutes. Hemodynamic parameters of the patient improved in hours and we were able to decrease the epinephrine and norepinephrine doses rapidly after ILI treatment. After ILI treatment, consequent blood gases and biochemical values are given in (Table I). At the $24^{\text {th }}$ hour of the PICU admission, the patient's vital signs, blood gases, blood glucose, biochemical parameters, and electrocardiogram findings returned to normal, and she was extubated.

At the end of the $24^{\text {th }}$ hour, all therapies were discontinued. The Patient was transferred to the pediatric ward on the $2^{\text {nd }}$ day and she was discharged on the $3^{\text {rd }}$ day of admission with full recovery.

Written informed consent was obtained from the parents of the patient

Table I. The patient's blood gases and certain biochemical values after ILI treatment.

\begin{tabular}{lccccccccc}
\hline & $\mathrm{pH}$ & $\mathrm{PCO} 2$ & $\mathrm{HCO} 3$ & Lactate & BUN & Creatinine & AST & ALT & ILI treatment \\
\hline 0.hour & 7.10 & 45 & 13.5 & 5.2 & 13 & 0.55 & 174 & 83 & \\
2.hour & 7.39 & 45.2 & 27.2 & 7.0 & 10 & 0.38 & 135 & 78 & $1.5 \mathrm{CC} / \mathrm{KG}^{*}$ \\
4.hour & 7.50 & 28.4 & 23.8 & 3.9 & & & & & \\
8.hour & 7.45 & 34.7 & 23.3 & 2.2 & 7 & 0.27 & 80 & 61 & \\
24.hour & 7.38 & 36.1 & 21.2 & 2.8 & 7 & 0.20 & 54 & 54 &
\end{tabular}

BUN: blood urea nitrogen, AST: aspartate aminotransferase, ALT: alanine aminotransferase, ILI: intravenous lipid infusion 


\section{Discussion}

Propranolol overdoses have potentially lifethreatening effects such as bradycardia, hypotension and CA similar to CCBs. ${ }^{5,6}$ At the same time BBs can cause toxic effects regardless of dose. Initial therapy in BBs poisoning is similar to other toxic drugs; determine and support the airway, breathing and circulation (ABC) troubles. In symptomatic patients IV glucagon (initially in reversal of BB symptoms) and calcium (especially in calcium channel blocker poisoning), fluid therapy, atropine, and inotropes are basics therapies., ${ }^{4,6,7}$ In our case, hyperinsulinemic euglycemia treatment and ILI were applied when there was no response to symptomatic treatment in the case of cardiovascular collapse following a high dose of BB intake.

ILI therapy is also highly recommended as a salvage treatment for severe poisoning with lipophilic anesthetic and other drugs. ${ }^{8}$ Sebe et al. ${ }^{5}$ reported a series of 15 adult patients who were treated with ILI secondary to BB, CCB, and paracetamol intoxication, 14 of them recovered, whereas one patient died. Le Fevre et al. ${ }^{9}$ reported a case of a 25 -year-old patient with a dramatic response to ILI following pulseless electrical activity arrest due to a mixed amitriptyline and propranolol overdose. Amanda et al. ${ }^{10}$ reported a complete clinical recovery with the administration of ILE in combination with high-dose insulin (HDI) in a 7-month-old symptomatic pediatric patient with acute propranolol toxicity. But their case was that of multidrug poisoning and it is unclear which drug caused the cardiotoxicity. Differently, our case only took propranolol leading to CA and our patient fully recovered with ILI treatment.

Rarely, BB and CCB poisoning does not respond to standard treatment, these intoxications may be fatal and extracorporeal support like ECMO and plasma exchange (PEX) may be needed. ${ }^{6,9,11}$ Kolcz et al. ${ }^{11}$ reported a case of 15-year-old girl with cardiogenic shock after alcohol, propranolol and verapamil overdose. Their patients successfully recovered with ECPR and PEX.

Our patient did not respond to fluids or high dose inotropic support and although we prepared for ECMO this was not necessary as she regained spontaneous circulation after 20 minutes of CPR. We didn't consider any extracorporeal therapies because our patient's clinical situation recovered rapidly after ILI treatment.

In conclusion, $\mathrm{BB}$ poisoning can be lifethreatening by causing cardiovascular collapse in children. When patients are unresponsive to the classical treatment options in these poisonings ILI treatment should be considered.

\section{Author contribution}

The authors confirm contribution to the paper as follows: study conception and design: EB, EG; data collection: EB, SB; analysis and interpretation of results: EB,TK,MR; draft manuscript preparation: TK,ET. All authors reviewed the results and approved the final version of the manuscript.

\section{Conflict of interest}

The authors have no potential conflict of interest with the present article.

\section{REFERENCES}

1. Farzam K, Jan A. Beta Blockers. Last Update: July 9, 2021. Available at: https://www.ncbi.nlm.nih.gov/ books/NBK532906/ (Accessed on September 20, 2021)

2. Brubacher JR. Chapter $61 \beta$-Adrenergic Antagonists. In: Nelson LS, Lewin NA, Howland MA, Hoffman RS, Goldfrank LR, Flomenbaum NE (eds). Goldfrank's Toxicologic Emergencies (9th ed) New York: McGraw-Hill, 2011.

3. Ozcan MS, Weinberg G. Intravenous lipid emulsion for the treatment of drug toxicity. J Intensive Care Med 2014; 29: 59-70. 
4. Graudins A, Lee HM, Druda D. Calcium channel antagonist and beta-blocker overdose: antidotes and adjunct therapies. Br J Clin Pharmacol 2016; 81: 453461.

5. Barrueto FJ. Beta blocker poisoning. UpToDate. 2018. Available at: https://www.uptodate.com/contents/ beta-blocker-poisoning. (Accessed on November 04, 2020).

6. Sebe A, DişelNR, Açıkalın Akpınar A, Karakoç E. Role of intravenous lipid emulsions in the management of calcium channel blocker and $\beta$-blocker overdose: 3 years experience of a university hospital. Postgrad Med 2015; 127: 119-124.

7. Seegobin K, Maharaj S, Deosaran A, Reddy P. Severe beta blocker and calcium channel blocker overdose: role of high dose insulin. Am J Emerg Med 2018; 36: 736.e5-736.e6.
8. Weinberg G. Lipid rescue resuscitation from local anaesthetic cardiac toxicity. Toxicol Rev 2006; 25: 139-145.

9. Le Fevre P, Gosling M, Acharya K, Georgiou A. Dramatic resuscitation with Intralipid in an epinephrine unresponsive cardiac arrest following overdose of amitriptyline and propranolol. BMJ Case Rep 2017; 2017: bcr2016218281.

10. Thompson AM, Franco Palacios CR, Henriksen MN. Intravenous lipid emulsion and high-dose insulin as adjunctive therapy for propranolol toxicity in a pediatric patient. Am J Health Syst Pharm 2016; 73: 880-885.

11. Kolcz J, Pietrzyk J, Januszewska K, Procelewska M, Mroczek T, Malec E. Extracorporeal life support in severe propranolol and verapamil intoxication. J Intensive Care Med 2007; 22: 381-385. 